\title{
A multi-factor model of panic disorder: Results of a preliminary study integrating the role of perfectionism, stress, physiological anxiety and anxiety sensitivity
}

\author{
Cristina M. Wood ${ }^{1 *}$; Antonio Cano-Vindel ${ }^{1}$ y José M. Salguero² \\ 1 Faculty of Psychology, Somosaguas Campus, Complutense University of Madrid (Spain). \\ 2 Faculty of Psychology, University of Malaga Spain.
}

\begin{abstract}
Título: Modelo multifactorial del trastorno de pánico: resultados de un estudio preliminar sobre el papel del perfeccionismo, estrés, ansiedad fisiológica y sensibilidad a la ansiedad.

Resumen: Antecedentes: el trastorno de pánico (TP) es un desorden mental altamente prevalente e incapacitante asociado a diferentes factores como el perfeccionismo, estrés, ansiedad fisiológica, y sensibilidad a la ansiedad referente a preocupaciones físicas; sin embargo, no existen estudios que hayan analizado conjuntamente la relación entre dichos factores y el TP en un modelo multifactorial utilizando ecuaciones estructurales. Método: con el objetivo de recoger información sobre estos factores y síntomas autoinformados de TP en el último año según criterios DSM-IV, se llevó a cabo un estudio transversal en una amplia muestra de la población general $(N=936)$. Resultados: el estrés percibido tuvo un efecto significativo a la hora de incrementar la ansiedad fisiológica, que a su vez se asoció de modo importante con las preocupaciones físicas. El perfeccionismo y el estrés percibido se relacionaron indirectamente con el TP durante el último año a través del efecto mediador de la ansiedad fisiológica y las preocupaciones físicas. Las preocupaciones físicas, por un lado, parece ser que mediaron el impacto entre el perfeccionismo y el TP y, por otro lado, mediaron parcialmente la relación entre ansiedad fisiológica y TP. Conclusiones: a pesar de la evidencia existente acerca de la relación entre cada uno de estos factores y el TP, se puede considerar este modelo como un marco teórico que recoge la investigación de forma conjunta y productiva sobre la naturaleza y tratamiento del TP.

Palabras clave: Sensibilidad a la ansiedad; trastorno de pánico; perfeccionismo; ansiedad fisiológica; estrés.
\end{abstract}

\section{Introduction}

Panic disorder (PD) is a highly comorbid, prevalent, disabling and chronic condition that negatively affects a person's quality of life (Roy-Byrne, Craske, \& Stein, 2006). An individual may begin to suffer from PD when he/she experiences repeated panic attacks (intense, unexpected and sudden feelings of fear accompanied by 4 or more uncontrolled anxiety symptoms, such as chest pain, dizziness, nausea and trembling, that develop rapidly and reach a peak in several minutes) along with any of the following: at least one month of constant concern, excessive worry about the negative consequences of the panic attacks or a significant behavioural change in relation to the attacks (APA, 2000).

Various factors have been proposed as explanations for the onset of PD, including perceived stress, physiological anxiety, anxiety sensitivity and, more recently, perfectionism. In the following section we analyze and discuss each of these explanatory factors.

A high frequency of stressful life events often precedes the onset of PD (Scocco, Barbieri, \& Frank, 2007). Similarly, PD and other anxiety disorders are associated to work and

* Dirección para correspondencia [Correspondence address]: Cristina Mae Wood. Dpto. Psicología Básica II (Procesos Cognitivos) buzón 23. Facultad de Psicología, Universidad Complutense de Madrid. 28223 Madrid (Spain). E-mail: wood@psi.ucm.es

\begin{abstract}
Background: Panic disorder (PD) is a highly prevalent and disabling mental health problem associated with different factors including perfectionism, stress, physiological anxiety, and anxiety sensitivity regarding physical concerns; however, no studies have analyzed the joint relationship between these factors and PD in a multi-factor model using structural equation modeling. Method: A cross-sectional study was carried out to collect data on these factors and self-reported DSM-IV past-year PD symptoms in a large sample of the general population $(N=936)$. Results: Perceived stress had a significant effect in increasing physiological anxiety, which in turn had an important association with physical concerns. Perfectionism and perceived stress had an indirect relation with past year PD via the mediator role of physiological anxiety and physical concerns. Physical concerns, on one hand, seemed to mediate the impact between perfectionism and PD and, on the other, partially mediated the role between physiological anxiety and PD. Conclusions: Although there is considerable evidence on the association between each of these factors and PD, this model can be considered a broader and productive framework of research on the nature and treatment of PD.
\end{abstract}

Key words: Anxiety sensitivity; panic disorder; perfectionism; physiological anxiety; stress. non-work stressors (Clark et al., 2012). It has been shown that after suffering stressful situations, some individuals may pay more attention to their physiological sensations and interpret them as threatening when under stress, which in turn may generate higher levels of anxiety and even panic attacks (Rapee, Litwin, \& Barlow, 1990). In other words, they may end up reacting to some stressful events in the same way as others might react to truly dangerous physical threats. Hence, stressors can precede the onset of and potentially increase the susceptibility to PD in some individuals (Spatola et al., 2010; Taylor, 2000). Nevertheless, this line of research has not defined the cognitive and personality factors that render an individual more vulnerable to develop PD.

With regard to physiological anxiety, when PD patients are exposed to everyday stressful events, they are more sensitive to bodily changes and experience more frequent distress than those with generalized anxiety disorder and nonanxious controls, even though their objective physiologic responses are comparable in intensity (Hoehn-Saric, McLeod, Funderburk, \& Kowalski, 2004). These findings imply that the perception of panic attacks reflects central rather than peripheral responses; hence, self-reported physiological anxiety which includes a biased interpretation on behalf of the individual suffering panic attacks can play a more important role in PD than objective physiological responses, as it may mediate the relation between stress and PD. In fact, according to a study carried out by Would, Zhang, Becker, McNal- 
ly, and Margraf (2014) with a sample of 1538 German women, a panic-related interpretation bias predicts the onset of PD. Consequently, subjective perceptions of stress and physiological anxiety appear to be important variables that should be included in a PD explanatory model.

In addition to perceived stress and physiological anxiety, there is an important cognitive variable for panic-related psychopathology known as anxiety sensitivity that denotes the extent to which an individual believes that symptoms of anxiety or physiological anxiety can have harmful consequences (Plehn \& Peterson, 2002; Taylor, 1999). In the presence of stress, anxiety sensitivity scores seem to predict spontaneous panic attacks (Zvolensky, Kotov, Antipova, \& Schmidt, 2005), even after controlling for history of panic attacks and trait anxiety (Schmidt, Lerew, \& Jackson, 1997). In the case of PD patients, there is evidence that they focus their fear of suffering anxiety onto the possibility of a future panic attack and that this condition is what accounts for the development of a clinical disorder (Barlow, 2004). It has also been shown that anxiety sensitivity scores predict the maintenance of PD among untreated patients, the future emergence of panic attacks among nonclinical panickers and the appearance of panic among individuals free from a history of panic attacks (Ehlers, 1995; Taylor \& Cox, 1998). More specifically, several studies indicate that a high anxiety sensitivity physical concerns score (rather than the other two dimensions of anxiety sensitivity known as cognitive concerns and social concerns, or the total score of the three dimensions altogether) not only predicts panic symptoms when an individual is exposed to his/her own physiological arousal but is also associated with a higher risk for PD (Brown, Smits, Powers, \& Telch, 2003; Grant, Beck, \& Davila, 2007). In other words, physical concerns seem to mediate the relation between physiological anxiety and PD as the occurrence of a stressproduced isolated panic attack should not lead to PD if one does not become anxious or scared about it happening again.

A personality factor that has been associated with several anxiety disorders, including PD, is perfectionism (Egan, Wade, \& Shafran, 2011; Frost \& Steketee, 1997; Oros, 2005; Saboonchi, Lundh, \& Ost, 1999). Perfectionism can be defined as the desire to achieve the highest standards of performance and control, together with unduly critical evaluations of one's own performance (Frost, Marten, Lahart, \& Rosenblate, 1990). There is evidence to support that individuals who demand perfection of themselves perceive more situations as threatening and are likely to feel more anxious, depressed, angry, and unsatisfied with their performance than non-perfectionist people as they constantly set demands that they are unable to meet, which in turn increases their probability of suffering stress (Antony \& Swinson, 1998; Kawamura, Hunt, Frost, \& Di Bartolo, 2001). The typical cognitions and presumably the associated emotions of perfectionists seem to contribute independently to stressinduced bodily responses (Wirtz et al., 2007), which in turn may be interpreted as an impending danger or a sign of per- sonal lack of control in those individuals with physical concerns, increasing in this way their possibility of developing PD. Although psychological models of PD have not included perfectionism as a relevant triggering factor (Barlow, 2004; Clark, 1986), individuals suffering from PD show higher perfectionism scores than nonanxious controls (Antony, Purdon, Huta, \& Swinson, 1998).

Even though the previously analyzed variables (perceived stress, physiological anxiety, physical concerns and perfectionism) have been shown to be associated with PD in independent studies, they have never been examined altogether in a multi-factor model using a large sample of the general population to understand their direct or indirect relation with PD. The objective of this study was to analyze the joint relationship between perceived stress, physiological anxiety, physical concerns, perfectionism and PD in a multifactor model using structural equation modeling (SEM). We expected perceived stress to be associated with physiological anxiety and this heightened physiological anxiety to be related with PD through the mediation of physical concerns. In addition, we hypothesized that perfectionism would be directly associated with stress and indirectly associated with PD through the mediation of physiological anxiety and physical concerns.

\section{Method}

\section{Participants}

Participants in the study were a non-random sample of 936 Spanish adults (49.3\% female, 50.7\% male) aged from 18 to $64(M=37.08, S D=11.05)$. Of them, $48.1 \%$ were single, $44.9 \%$ were married, $6 \%$ were divorced and $1 \%$ widowed. With respect to the educational level, 5.3\% had elementary studies, $11.9 \%$ junior high school studies, $36.7 \%$ senior high school, $33.9 \%$ university studies, and $12.2 \%$ post-graduate studies.

\section{Procedure}

This study is part of a larger project designed to assess cognitive variables associated with anxiety disorders in the general population. Participants were approached in different work settings (with the knowledge and approval of their superiors) starting from an extended group that included more than thirty collaborators (all members of a scientific society from different cities in Spain) who resent the questionnaire to friends and coworkers. Upon receiving informed consent, survey instruments were sent via e-mail to the participants with instructions given in writing. They were offered a telephone number and en e-mail address in case they had any questions. Participation in the research project was thus entirely voluntary and anonymity was guaranteed. Participants were not given any kind of incentive for participating in the study and were offered the possibility of receiving the results of the assessment. 


\section{Instruments}

The battery of tests were administered in Spanish and they assessed, as part of a broader investigation on PD prevalence and associated factors, levels of perceived stress, physiological anxiety, anxiety sensitivity-physical concerns, perfectionism, and DSM-IV criteria for PD.

Perceived stress was assessed with three simple items referring to essential aspects of the stress response: perceived intensity of stress, the existence of stressful life events, and the degree of stress/anxiety due to excessive demands (demands and control imbalance). It was designed ad hoc for this investigation in the form of statements referring to the past year (i.e., "How stressed have you been?"; "Have you suffered important problems that have negatively affected your life?"; "How much pressure/anxiety have you felt due to different demands, responsibilities, lack of time, or any other factors related to stress?") on a 5-point response Likert scale (from $0=$ almost never to $4=$ almost always) which was summed up for each participant. Internal consistency (Cronbach's alpha) was .85 .

The Physiological Anxiety subscale of the brief version of the Inventory of Situations and Responses of Anxiety (ISRA-B; Miguel-Tobal \& Cano-Vindel 2007), was used to assess physiological anxiety. This subscale is composed of 10 items that assess the frequency with which an individual reacts anxiously (e.g., "My heart beats rapidly"; "I feel my hands or other parts of my body sweat, even on cold days"), in general, according to a 5-point Likert scale (from $0=$ almost never to $4=$ almost always). It has shown sound psychometric properties given its adequate factor structure displaying good model fit, its excellent internal consistency (Cronbach's alpha $=.86), 2$-month test-retest reliability $(r=$ $.61)$, adequate convergent validity, as well as a good discriminant capacity between patients with anxiety disorders and non-clinical populations (Miguel-Tobal \& Cano-Vindel 2007). Cronbach's alpha in this study was .87 .

Physical concerns were measured with the Anxiety Sensitivity Index (ASI; Peterson \& Reiss, 1992). The ASI encompasses three distinct dimensions: physical, cognitive and social concerns. In our survey, we analysed 6 of the 18 items included in the Spanish version of the ASI (ASI-3; Sandín, Valiente, Chorot, \& Santed, 2007), corresponding to the physical concerns scale (e.g., "When I feel pain in my chest, I worry that I'm going to have a heart attack"). The psychometric properties of the Spanish version of this instrument with respect to reliability (internal consistency and testretest) and validity (convergent and discriminant) are sound (Sandín et al., 2007), with an alpha value of .84 for physical concerns. In our study, Cronbach's alpha was .90.

The Multidimensional Perfectionism Scale developed by Frost et al. (1990) was the first measure designed to assess perfectionism in six different dimensions: a) concern over mistakes, b) doubts about actions, c) personal standards, d) parental expectations, e) parental criticism, and f) organization, including 36 items in total. In our study, perfectionism was assessed through a brief six-item scale (in order to reduce fatigue) designed ad hoc to tap these six different dimensions of perfectionism in the form of statements with a 5-point Likert response format from 0 to 4 (e.g., "Do you have a tendency to react negatively to mistakes and to equate mistakes with failure?"; "Do you have a tendency to doubt about the quality of your performance?"). Responses were summed up for each participant and Cronbach's alpha was .79 .

Questions about panic attacks were based on the DSMIV criteria (APA, 2000) with a dichotomous response format (e.g., "Have you ever experienced a particularly strong anxiety response -or panic attack- accompanied by a sudden sense of fear or nervousness or an unexpected large number of physical symptoms?"; "If the answer is yes, has this crisis ever happened unexpectedly in a situation where you would normally feel calm and comfortable?"; "Did it develop abruptly?"; "Did it reach a peak within 10 minutes?"). If the answers to these questions were affirmative, respondents were asked to checkmark all the symptoms they had experienced in their panic attack(s) from a list. Self-reported past year PD criteria was assessed by asking respondents about the frequency of their panic attacks during the last month and past year and whether or not they had suffered the following for at least one month: a) persistent concern about suffering another panic attack, b) worry about the potential consequences of the attack and c) a behavioral change in relation to the attacks. Convergent validity for these questions was studied in a small subsample of forty people using the Structured Clinical Interview for DSM-IV Axis I Disorders (SCID-I; First, Spitzer, Gibbon, \& Williams, 1996); some of the questions were modified and others were included until a good convergence was obtained with the diagnosis of PD according to the SCID-I.

\section{Data Analyses}

The statistical package SPSS was used for computing descriptive statistics and internal consistency. Mplus version 5 (Muthén \& Muthén, 2007) was used to conduct path analysis, a SEM technique that only examines observed variables (Byrne, 1998). Given that the outcome in the model is dichotomous, a weighted least squares estimation procedure was used (MacKinnon, 2008). WLSMV corrects chi-square test of fit with dichotomous or ordinal observed variables (Muthén \& Satorra, 1995), provides stable estimates for large simple sizes and is appropriate for use with non-normal data (Flora \& Curran, 2004). In order to test our hypotheses, the following analytic procedure was undertaken. Firstly, path analysis was performed to test the fit of the hypothesized model. In case the model did not fit the data, modification indices provided were inspected to change the model in a theoretically consistent way. If at any stage a well-fitting model was found, no subsequent alterations were made. Finally, we explored total and indirect effects among the variables in the final model. In addition to the chi-square test, 
overall goodness of fit was evaluated using the following empirically supported fit indices: (a) the comparative fit index (CFI), (b) the Tucker-Lewis Index (TLI), (c) the root mean square error (RMSEA), and (d) the weighted root mean square residual (WRMR). Fit index cut-off values for well-fitting models have been suggested as CFI >.95, TLI $>.95$, RMSE $A<.06$, WRMR <.90 (Hu \& Bentler, 1999; Muthén \& Muthén, 2007).

\section{Results}

\section{Descriptive Analysis}

Table 1 displays descriptive analyses regarding key variables in the model. Internal consistency (Cronbach's alpha) was satisfactory for all the variables, ranging from .79 (for perfectionism) to .90 (for physical concerns). Past-year prevalence of PD was $2.4 \%$.

Path analysis testing the associations among perfectionism, perceived stress, physiological anxiety, physical concerns and past-year PD

Key variables were included in the model; thus, our model contained 5 observed variables. The hypothesized model did not provide a good fit to the data, $\chi 2(d f=5)=$ 59.24, $p<.001, C F I=.92 ;$ TLI $=.89 ;$ RMSE $A=.11$; $W R M R=2.01$. In order to obtain a well-fitting model, the modification indices were inspected. The largest modification indexes were a direct path from physiological anxiety to past-year PD, a direct path from perfectionism to physiological anxiety, and a direct path from perfectionism to physical concerns. The model was re-specified to include these paths. After changes, the final model resulted in a good fit with the data $\left(\chi^{2}(d f=3)=3.84, p<.05\right), C F I=1.00 ; T L I=1.00$; RMSE $A=.02 ; W R M R=.44$. Figure 1 presents the final model with standardized beta coefficients displayed.

Table 1 . Key study variables.

\begin{tabular}{lll}
\hline Variables in the model & $\%$ & $N$ \\
\hline Past-Year Panic Disorder & & \\
No & 97.6 & 914 \\
Yes & 2.4 & 22 \\
\hline Variables in the model & $M(S D)$ & Alpha coefficient \\
\hline Perfectionism & $8.10(4.47)$ & .79 \\
Perceived Stress & $5.20(3.43)$ & .85 \\
Physiological Anxiety & $6.15(6.12)$ & .87 \\
Physical concerns & $2.80(4.12)$ & .90 \\
\hline
\end{tabular}

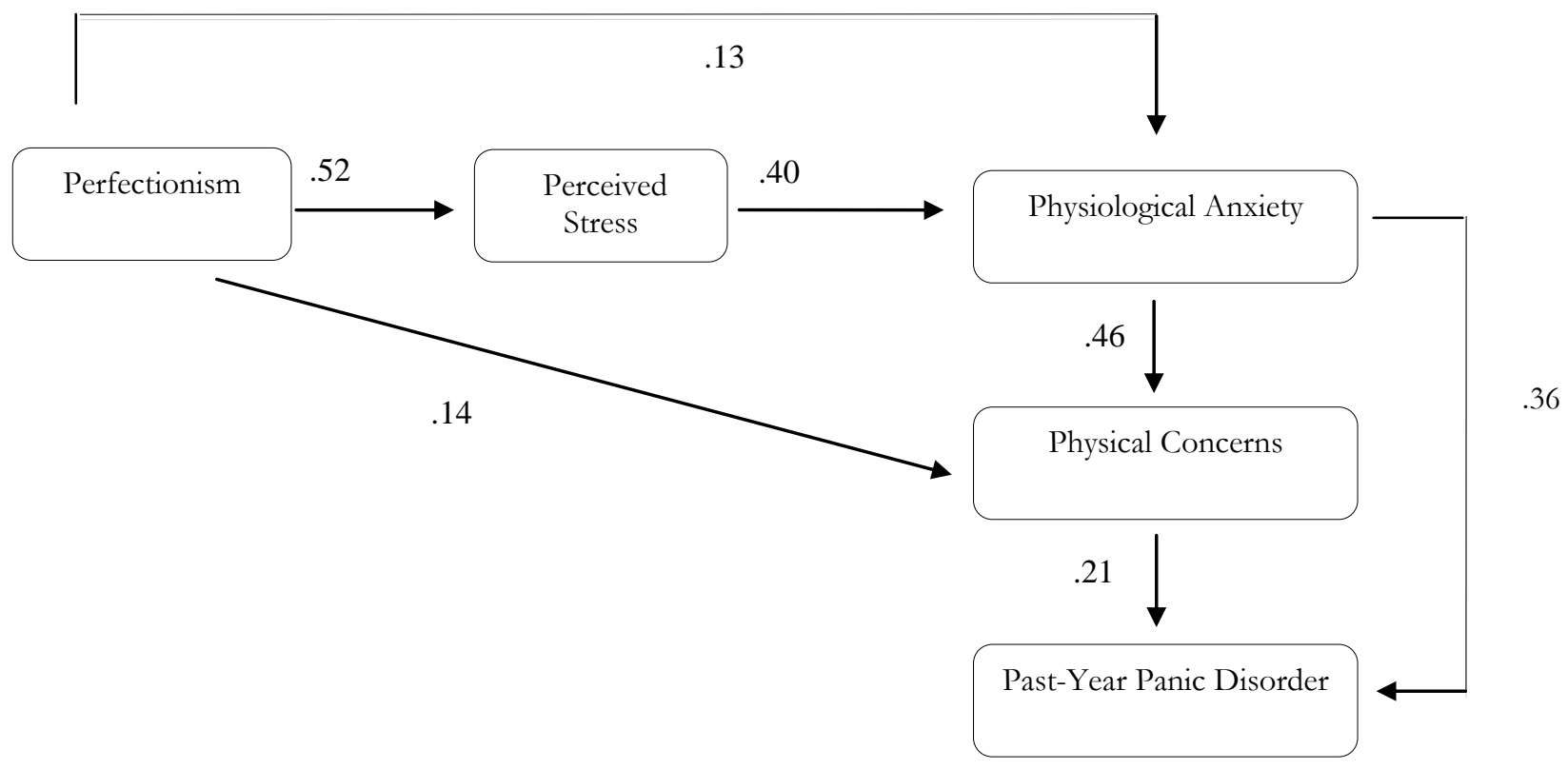

Figure 1. Final structural equation model for past-year panic disorder.

Note: all standardized beta coefficients are significant at $p<.01$

We inspected the total and indirect effects among the variables in the final model. Results are shown in Table 2. Indirect but no direct effects were found between both perfectionism and perceived stress and past-year PD. On the other hand, perceived stress had an indirect effect on physi- cal concerns, while perfectionism was directly and indirectly related to both physiological anxiety and physical concerns. In sum, the final model showed that elevated levels of perfectionism were directly associated with higher physiological anxiety, more physical concerns and, mainly, with an in- 
creased level of perceived stress. Perceived stress was positive and strongly associated with physiological anxiety, which was directly and indirectly (via physical concerns) related to past-year PD. Finally, physical concerns showed a direct ef- fect on PD. While both the level of perfectionism and perceived stress showed a significant relation with PD, this association was mediated by the rest of the variables in the model.

Table 2. Total and indirect effects among variables in the model.

\begin{tabular}{lcccccc}
\hline & \multicolumn{2}{c}{ Physiological Anxiety } & \multicolumn{2}{c}{ Physical Concerns } & \multicolumn{2}{c}{ Past-Year Panic Disorder } \\
\cline { 2 - 6 } & Total effect, $\beta$ & Indirect effect, $\beta$ & Total effect, $\beta$ & Indirect effect, $\beta$ & Total effect, $\beta$ & Indirect effect, $\beta$ \\
\hline Perfectionism & .35 & .22 & .30 & .16 & .19 \\
Perceived Stress & -- & -- & .18 & .18 & .18 \\
Physiological Anxiety & -- & -- & -- &.- & .18 & .45 \\
\hline
\end{tabular}

Note: all standardized beta coefficients are significant at $p<.01$

\section{Discussion}

Different cognitive models have been used to explain the onset and maintenance of PD by suggesting that exposure to stress increases physiological anxiety and that the individual tendency to misinterpret these physiological sensations as dangerous or harmful may increase the vulnerability of certain individuals to PD (Barlow, 2004). On the other hand, there is preliminary evidence on the association between perfectionism and PD. However, no study to date has examined the association of perceived stress, physiological anxiety, physical concerns and perfectionism with PD in a multifactor model.

Our results, obtained from a large sample of general population, indicate that perfectionism and perceived stress have an indirect relation with past year PD via the mediator role of physiological anxiety and physical concerns. Physical concerns (i.e., the belief that symptoms of anxiety can have harmful consequences), on one hand, seemed to mediate the impact between perfectionism and PD and, on the other, partially mediated the role between physiological anxiety and PD.

Even though previous studies have identified a direct association between perfectionism and PD (Antony et al., 1998), and between perceived stress and PD (Barlow, 2000), our results seem to point out that these relations are indirect in the sense that perfectionism and perceived stress may increase the perception of physiological anxiety and concern over physical symptoms, which in turn is associated with past year PD. The fact that physical concerns were found to partially mediate the association between physiological anxiety and PD could suggest that when an individual suffers frequent stress he/she is more likely to experience high levels of physiological anxiety and to interpret these symptoms as dangerous or harmful (interpretive bias) which in the long term increases the risk of developing PD. Nevertheless, given that this is a partially mediated association, there may be other mediator variables involved, such as information-processing biases. Results of a recently published longitudinal study are in line with this hypothesis (Woud et al., 2014) by revealing that women who interpreted ambiguous panic-related situations in a threatening manner at baseline were more likely to develop PD at follow-up than women without this interpretive bias, even after controlling for anxiety sensitivity and for fear of bodily sensations. Other authors have associated anxiety sensitivity with attentional, interpretive and memory biases (as cognitive risk factors for PD), however there is evidence that cognitive biases rarely correlate strongly with anxiety sensitivity (McNally, Hornig, Hoffman, \& Han, 1999).

Our findings lead us to highlight the importance of perceived stress and perfectionsim in the generation of high levels of physiological anxiety. The erroneous and catastrophic beliefs that perfectionistic individuals maintain when they interpret their bodily sensations as a sign of impending danger or loss of control during a stressful situation (e.g., believing that an increase in their heart rate is an unequivocal sign of a heart attack, or that feeling dizzy will undoubtedly lead to brain damage), may increase the chances of developing PD. Our results add evidence in favor of the cognitive models of panic with the particularity of including factors such as perfectionism, physiological anxiety and physical concerns that have turned out to be relevant variables with important direct and indirect effects in the development of PD, especially in the case of perfectionism which has been associated with higher levels of physiological anxiety and physical concerns.

Several limitations to the present study must be mentioned. In the first place, even though our sample was recruited from the general population it was not randomly selected and therefore generalizability of results may be limited. Second, due to the large number of items included in the battery of tests, some measures were created ad hoc with a reduced number of items, in order to diminish the possiblity of questionnaire fatigue. Future studies should replicate these findings using other measures with higher validity; nevertheless, our measures have shown good reliability. Third, since past-year PD was measured with a questionnaire instead of a clinical interview, the prevalence estimate of $2.4 \%$ may be inflated. Fourth, even though we hypothesized that all factors under study could have an impact on PD, we did not carry out a longitudinal or experimental study and, as a result, we cannot draw meaningful inferences about cause and effect. Nevertheless, our findings are in line with previous studies linking perceived stress, physiological anxiety, physical concerns and 
perfectionism to PD and provide new insights regarding the development of PD.

There are important practical implications that can be extracted from these preliminary results. In the first place, clinicians should inform PD patients about the negative role played by perfectionism in their levels of perceived stress and how stress is related to anxiety (Aldea, Rice, Gormley, \& Rojas, 2010; O'Connor, Rasmussen, \& Hawton, 2010). Patients should be aware of the fact that anxiety sensitivity has been found to have a small negative relationship with treatment outcome (El Alaoui et al., 2013), suggesting that anxiety sensitivity may slightly enhance treatment response. Existing evidence also shows that perfectionism and anxiety sensitivity is responsive to treatment and that it produces positive changes in perceived levels of anxiety and stress

\section{References}

Aldea, M. A., Rice, K. G., Gormley, B., \& Rojas, A. (2010). Telling perfectionists about their perfectionism: Effects of providing feedback on emotional reactivity and psychological symptoms. Behaviour Research and Therapy, 48, 1194-1203. Doi:10.1016/j.brat.2010.09.003

American Psychiatric Association. (2000). Diagnostic and statistical manual of mental disorders (4th ed., text revision). Washington, DC: Author.

Antony, M. M., Purdon, C. L., Huta, V., \& Swinson, R. P. (1998). Dimensions of perfectionism across the anxiety disorders. Behaviour Research and Therapy, 36, 1143-1154. Doi:10.1016/S0005-7967(98)00083-7

Antony, M. M., \& Swinson, R. P. (1998). When perfect isn't good enough. Strategies for coping with perfectionism. Oakland, CA: New Harbinger.

Barlow, D. H. (2000). Unraveling the mysteries of anxiety and its disorders from the perspective of emotion theory. American Psychologist, 55, 1247 63. Doi:10.1037/0003-066X.55.11.1247

Barlow, D. H. (2004). Anxiety and its disorders: The nature and treatment of anxiety and panic (2nd ed.). New York: Guilford.

Brown, M., Smits, J. A., Powers, M. B., \& Telch, M. J. (2003). Differential sensitivity of the three ASI factors in predicting panic disorder patients' subjective and behavioral response to hyperventilation challenge. Journal of Anxiety Disorders, 17, 583-591. Doi:10.1016/S0887-6185(02)00231-1

Byrne, B. M. (1998). Structural equation modeling with Lisrel, Prelis and Simplis: Basic concepts, applications, and programming. Mahwah, NJ: Lawrence Erlbaum.

Clark, D. M. (1986). A cognitive approach to panic. Behaviour Research and Therapy, 24, 461-470.

Clark, C., Pike, C., McManus, S., Harris, J., Bebbington, P., Brugha, T., ...Stansfeld (2012). The contribution of work and non-work stressors to common mental disorders in the 2007 Adult Psychiatric Morbidity Survey. Psychological Medicine, 42, 829-842. Doi:10.1017/S0033291711001759

Egan, S. J., Wade, T. D., \& Shafran, R. (2011). Perfectionism as a transdiagnostic process: A clinical review. Clinical Psychology Review, 31, 203-212. Doi:10.1016/j.cpr.2010.04.009

Ehlers, A. (1995). A 1-year prospective study of panic attacks: clinical course and factors associated with maintenance. Journal of Abnormal Psychology, 104, 164-72. Doi:10.1037/0021-843X.104.1.164.

El Alaoui, S., Hedman, E., Ljotsson, B., Bergstrom, J., Andersson, E., Ruck, C.,...Lindefors, N. (2013). Predictors and moderators of internet- and group-based cognitive behaviour therapy for panic disorder. PLoS One, 8, e79024. Doi: 10.1371/journal.pone.0079024

First, M. B., Spitzer, R. L., Gibbon, M., \& Williams, J. B. W. (1996). Structured Clinical Interview for Axis I DSM-IV Disorders-Patient Edition (SCID-I/P Version 2.0). New York: Biometrics Research Department.

Flora, D., \& Curran, P. (2004). An empirical evaluation of alternative methods of estimation for confirmatory factor analysis with ordinal data. Psychological Methods, 9, 466-491. Doi:10.1037/1082-989X.9.4.466
(Egan et al., 2011; McNally, 2002; Radhu, Daskalakis, ArpinCribbie, Irvine, \& Ritvo, 2012). In addition, changes in intraindividual anxiety sensitivity during cognitive behavioural treatment predict subsequent intraindividual changes in panic symptoms (Gallagher et al., 2013). Thus, appart from targeting anxiety sensitivity and physiological anxiety, cognitive therapy should include specific exercises and cognitive techniques to help PD patients reduce their levels of perfectionism, subjective threat and perceived stress.

Acknowledgements.- This investigation has been carried out under the financial sponsorship of the research project "Anxiety crises: Prevalence and vulnerability factors" funded by the Ministry of Science and Innovation MICINN (ref. PSI 2008-05332).

Frost, R. O. Marten, P., Lahart, C., \& Rosenblate, R. (1990). The dimensions of perfectionism. Cognitive Therapy and Research, 19, 195-206. Doi:10.1007/BF01172967

Frost, R. O., \& Steketee, G. (1997). Perfectionism in obsessive-compulsive disorder patients. Behaviour Research and Therapy, 35, 291-296. Doi:10.1016/S0005-7967(96)00108-8

Gallagher, M. W., Payne, L. A., White, K. S., Shear, K. M., Woods, S. W., Gorman, J. M., \& Barlow, D. (2013). Mechanisms of change in cognitive behavioral therapy for panic disorder: the unique effects of selfefficacy and anxiety sensitivity. Behaviour Research and Therapy, 51, 767777. Doi: 10.1016/j.brat.2013.09.001

Grant, D. M., Beck, J. G., \& Davila, J. (2007). Does anxiety sensitivity predict symptoms of panic, depression, and social anxiety? Behaviour Research and Therapy, 45, 2247-2255. Doi:10.1016/j.brat.2007.02.008

Hoehn-Saric, R., McLeod, D. R., Funderburk, F., \& Kowalski, P. (2004). Somatic symptoms and physiologic responses in generalized anxiety disorder and panic disorder: an ambulatory monitor study. Archives of General Psychiatry, 61, 913-921. Doi:10.1001/archpsyc.61.9.913

Hu, L. T., \& Bentler, P. M. (1999). Cut off criteria for fit indexes in covariance structure analysis: Conventional criteria versus new alternatives. Structural Equation Modeling, 6, 1-55. Doi:10.1080/10705519909540118

Kawamura, K. Y., Hunt, S. L., Frost, R. O., \& Di Bartolo, P. M. (2001). Perfectionism, anxiety, and depression: Are the relationships independent? Cognitive Therapy and Research, 25, 291-301. Doi:10.1023/A:1010736529013

MacKinnon, D. P. (2008). Introduction to statistical mediation analysis. Mahwah: Erlbaum.

McNally, R. J. (2002). Anxiety sensitivity and panic disorder. Biological Psychiatry, 52, 938-46. Doi:10.1016/S0006-3223(02)01475-0

McNally, R. J., Hornig, C. D., Hoffman, E. C., \& Han, E. M. (1999). Anxiety sensitivity and cognitive biases for threat. Behavior Therapy, 30, 51-61. Doi:10.1016/S0005-7894(99)80045-8

Miguel-Tobal, J. J., \& Cano-Vindel, A. (2007). Inventario de situaciones y respuestas de ansiedad (ISRA): Manual (6 rev. ed.) Inventory of Situations and Responses of Anxiety: Manual]. Madrid: TEA.

Muthén, B.O., \& Muthén, L.K. (2007). Mplus (Version 5). Los Angeles: California.

Muthén, B. O., \& Satorra, A. (1995). Technical aspects of Muthen's LISCOMP approach to estimation of latent variable relations with a comprehensive measurement model. Psychometrika, 60, 489-503. Doi:10.1007/BF02294325

O'Connor, R. C., Rasmussen, S., \& Hawton, K. (2010). Predicting depression, anxiety and self-harm in adolescents: the role of perfectionism and acute life stress. Behaviour Research and Therapy, 48, 52-59. Doi:10.1016/j.brat.2009.09.008 
Oros, L. (2005). Implicaciones del perfeccionismo infantil sobre el bienestar psicológico: orientaciones para el diagnóstico y la práctica clínica. Anales de Psicología, 21, 294-303. Doi:10.6018/26951

Peterson, R. A., \& Reiss, S. (1992). Anxiety Sensitivity Index Manual (2nd ed.). Worthington, $\mathrm{OH}$ : International Diagnostic Systems.

Plehn, K., \& Peterson, R. A. (2002). Anxiety sensitivity as a predictor of the development of panic symptoms, panic attacks, and panic disorder: a prospective study. Journal of Anxiety Disorders, 16, 455-474. Doi:10.1016/S0887-6185(02)00129-9

Rapee, R. M., Litwin, E. M., \& Barlow, D. H. (1990). Impact of life events on subjects with panic disorder and on comparison subjects. American Journal of Psychiatry, 147, 640-644.

Roy-Byrne, P. P., Craske, M. G., \& Stein, M. B. (2006). Panic Disorder. Lancet, 368, 1023-1032. Doi:10.1016/S0140-6736(06)69418-X

Saboonchi, F., Lundh, L. G., \& Ost, L. G. (1999). Perfectionism and selfconsciousness in social phobia and panic disorder with agoraphobia. Behaviour Research and Therapy, 37, 799-808. Doi:10.1016/S00057967(98)00183-1

Sandin, B., Valiente, R. M., Chorot, P., \& Santed, M. A. (2007). ASI-3: nueva escala para la evaluación de la sensibilidad a la ansiedad. Revista de Psicopatología y Psicología Clínica, 12, 91-104.

Schmidt, N. B., Lerew, D. R., \& Jackson, R. J. (1997). The role of anxiety sensitivity in the pathogenesis of panic: prospective evaluation of spontaneous panic attacks during acute stress. Journal of Abnormal Psychology, 106, 355-364. Doi:10.1037//0021-843X.106.3.355
Scocco, P., Barbieri, I., \& Frank, E. (2007). Interpersonal problem areas and onset of panic disorder. Psychopathology, 40, 8-13. Doi:10.1159/000096384

Spatola, C. A., Scaini, S., Pesenti-Gritti, P., Medland, S. E., Moruzzi, S., Ogliari, A., . . Battaglia, M. (2010). Gene-environment interactions in panic disorder and CO2 sensitivity: Effects of events occurring early in life. American Journal of Medical Genetics Part B: Neuropsychiatric Genetics, 156B, 79-88. Doi:10.1002/ajmg.b.31144

Taylor, S. (1999). Anxiety Sensitivity: Theory, Research, and Treatment of the Fear of Anxiety. Mahwah, NJ: Erlbaum.

Taylor, S. (2000). Understanding and treating panic disorder: Cognitive behavioural approaches. Chichester, UK: Wiley.

Taylor, S., \& Cox, B. J. (1998). An expanded anxiety sensitivity index: evidence for a hierarchic structure in a clinical sample. Journal of Anxiety Disorders, 12, 463-83. Doi:10.1016/S0887-6185(98)00028-0

Wirtz, P. H., Elsenbruch, S., Emini, L., Rudisuli, K., Groessbauer, S., \& Ehlert, U. (2007). Perfectionism and the cortisol response to psychosocial stress in men. Psychosomatic Medicine, 69, 249-255. Doi:10.1097/PSY.0b013e318042589e

Woud, M. L., Zhang, X. C., Becker, E. S., McNally, R. J., \& Margraf, J. Don't panic: Interpretation bias is predictive of new onsets of panic disorder. Journal of Anxiety Disorders, 28, 83-87. Doi: 10.1016/j.bbr.2011.03.031

(Article received: 14-10-2013; revised: 14-02-2014; accepted: 12-03-2014) 